\title{
UN MECANISMO DE INTEGRACIÓN FEDERAL Y CIUDADANA: LAS CONSULTAS «PRENORMATIVAS» DEL ORDENAMIENTO CONSTITUCIONAL SUIZO ${ }^{1}$
}

\author{
REMEDIO SÁNCHEZ FERRIZ \\ Catedrática de Derecho Constitucional \\ Universitat de Valencia
}

SUMARIO

I. Diversas manifestaciones del derecho de audiencia.

II. Papel y significación de las consultas.

III. Regulación.

IV. Fases del procedimiento de consulta.

V. Alguna valoración para concluir.

\section{DIVERSAS MANIFESTACIONES DEL DERECHO DE AUDIENCIA}

\section{Derecho a ser oído}

Entre nosotros es conocido el reconocimiento que el ordenamiento jurídico hace, en diversas ramas jurídicas y con diferente rango y naturaleza, del derecho a ser oído en el que, sin embargo, suele estar presente como elemento constitutivo del mismo la exigencia de un interés directo en el procedimiento de que se trate ${ }^{2}$.

En efecto, podemos hallar manifestaciones muy diversas en nuestro ordenamiento del derecho a ser oído: el trámite de audiencia en el procedimiento admi-

1 Estudio realizado en el marco del Proyecto MINECO «Régimen jurídico constitucional del Gobierno 2.0-Open Government. Participación y transparencia electrónicas y uso de las redes sociales por los poderes públicos» (DER2012-37844).

2 Por todas las manifestaciones en nuestro ordenamiento, baste recordar el art. 84 de la Ley 30/1992, de 26 de noviembre de Régimen jurídico de las Administraciones Publicas y del procedimiento administrativo común. 
nistrativo, derecho a la información en términos de legalidad y en diversos ámbitos (muy extendido hoy a través de la legislación de protección al consumidor) y, ya en el ámbito constitucional, el derecho a la información sobre cuestiones de naturaleza pública que el TC ha ido decantando entre las manifestaciones del derecho a la información reconocido en el art. 20. 1, d) de la Constitución; sin que quepa olvidar el art. 105, también de la Constitución, hoy por lo demás, colocado en primera línea de la política legislativa por la vía de la exigencia de transparencia ${ }^{3}$.

También existen diversas manifestaciones de la capacidad de hacerse presentes, como expresión popular, en determinados procedimientos como los de carácter urbanístico, en los que, a través de la acción popular, cabe incluso solicitar la incoación del procedimiento sancionador para los presuntos infractores. Ello sin perjuicio, o a mayor abundamiento de la general aplicación también en estos casos del derecho de audiencia que, sin embargo, no puede confundirse con el derecho de participación política como dejó claro el TC en la STC 119/1995, de 17 de julio, a la que me referiré infra.

\section{Las consultas populares}

En los últimos años, además, se ha popularizado en algunas Comunidades Autónomas la idea de las consultas que han alcanzado reconocimiento legal y hasta estatutario. En efecto, la Ley de consultas populares locales de Andalucía ${ }^{4}$, de 3 de mayo de 2001, las regula para el ámbito local calificándolas en su art. 2 como «el instrumento de conocimiento de la opinión de los vecinos sobre asuntos de la competencia propia municipal y de carácter local que sean de especial relevancia para sus intereses, sin que su resultado vincule a la Entidad Local convocante».

Con mayor amplitud (o indefinición) se pronuncia el Estatuto de Cataluña en su art. 122 al establecer que "Corresponde a la Generalitat la competencia exclusiva para el establecimiento del régimen jurídico, las modalidades, el proce-

3 Entre tantos, el mas reciente estudio de Rollnert, Goran, «La regulación del derecho de acceso a la información pública mediante ley ordinaria: problemática jurídico-constitucional», en Teoría y Realidad Constitucionall. UNED, Madrid, n. ${ }^{\circ}$ 34, 2014, pp. 349-368.

4 Como su propia exposición de motivos refiere se apoya en la Ley de régimen local y en el propio Estatuto: «En concreto, el artículo 71 de la Ley 7/1985, de 2 de abril, reguladora de las Bases de Régimen Local, establece la posibilidad de que los Alcaldes, previo acuerdo por mayoría absoluta del Pleno y autorización del Gobierno de la Nación, podrán someter a consulta popular aquellos asuntos de la competencia propia municipal y de carácter local que sean de especial relevancia para los intereses de los vecinos, con excepción de los relativos a la Hacienda Local. Asimismo, en su artículo 18, señala como uno de los derechos de los vecinos pedir la consulta popular en los términos previstos en la Ley. Por otra parte, el artículo 15.2 del Estatuto de Autonomía para Andalucía dispone que corresponde a la Comunidad Autónoma el desarrollo legislativo del sistema regulador de las consultas populares locales en el ámbito de Andalucía, de conformidad con lo que dispongan las leyes a que se refiere el apartado 3 del artículo 92 y los números 1 y 32 del artículo 149.1 de la Constitución, correspondiendo al Estado la autorización de su convocatoria. 
dimiento, la realización y la convocatoria por la propia Generalitat o por los entes locales, en el ámbito de sus competencias, de encuestas, audiencias públicas, foros de participación y cualquier otro instrumento de consulta popular, con excepción de lo previsto en el artículo 149.1.32 de la Constitución» ${ }^{5}$. Las fuertes implicaciones políticas con que se ha vinculado la aplicación de este precepto al derecho a decidir, con pretensiones secesionistas, excluye toda posibilidad de comparación con el procedimiento de consulta suizo en el que nos vamos a centrar

En estos ejemplos que se van iniciando (y reivindicando) en nuestro estado autonómico la idea de consulta va unida a la insatisfacción con el sistema representativo y, por consiguiente, a la de ampliación de participación política o de renovación democrática, en abierta contestación a la exclusividad de la participación de carácter representativo que domina el panorama constitucional; es decir, en las nuevas propuestas se intenta aportar mecanismos nuevos y complementarios a la participación indirecta o mediata que caracteriza nuestro sistema.

\section{Participación social ante las Cámaras}

En esta misma línea, también recientemente se ha llamado la atención sobre las vías de «audiencia» en la labor parlamentaria. Carrasco, por lo que se refiere a la eventual participación social en el procedimiento legislativo, acaba de recordarnos la pacata previsión del Reglamento del Congreso de los Diputados (y del Reglamento del Senado que, aun cuando es algo más generoso en su texto, no ha alcanzado en la práctica aplicación diferente a la del Congreso) al prever en su art. $44.4^{6}$

5 El TC en la sentencia 31/2010 por la que resolvía el recurso de inconstitucionalidad contra el Estatuto de 2006, declaro que no era inconstitucional el precepto a condición que se interpretara en la forma en que la propia sentencia establece en su Fundamento Jurídico 69 en el que, aplicando doctrina de la STC 103/2008, de 11 de septiembre, se distingue entre referéndum (competencia exclusiva del Estado) y consultas no referendarias: «Caben, pues, consultas populares no referendarias mediante las cuales «se recaba la opinión de cualquier colectivo sobre cualesquiera asuntos de interés público a través de cualesquiera procedimientos» distintos de los que cualifican una consulta como referéndum (STC 103/2008, FJ 2) y con los límites materiales a los que también hicimos referencia en la STC 103/2008 (FJ 4) respecto de todo tipo de consultas, al margen de la prevista en el art. 168 CE. Las encuestas, audiencias públicas y foros de participación a los que se refiere el art. 122 EAC tienen perfecto encaje en aquel género que, como especies distintas, comparten con el referéndum....». En todo caso, la reciente extrapolación de la consulta y su politización convierten el caso catalán en supuesto no parangonable con el que se trata de estudiar ahora.

6 Carrasco Durán, Manuel, «La participación social en el procedimiento legislativo», en Revista de Derecho Político, UNED, Madrid, n. ${ }^{\circ}$ 89, enero-abril 2014, pp. 177-178: El Reglamento del Congreso de los Diputados solamente admite, en su art. $44.4 .^{\circ}$, la posibilidad de que las comisiones, por conducto del Presidente de la Cámara, recaben la comparecencia de otras personas competentes en la materia, aparte de los miembros del Gobierno, autoridades y funcionarios públicos, a efectos de informar y asesorar a la comisión. Se trata, por tanto, de un artículo que da cobertura a la audiencia de técnicos en las materias objeto de debate, pero no prevé, al menos expresamente, la comparecencia de personas u organizaciones representativas de grupos sociales afectados por los proyectos y proposiciones de ley. El segundo párrafo del art. 67 del Reglamento del Senado tiene un ámbito más amplio, ya que prevé que las comisiones podrán solicitar la presencia, en general, de otras personas, además de miembros del Gobierno y de sus Departamentos y cualesquiera autori- 
la posibilidad de que las Comisiones, por conducto del Presidente del Congreso, recaben la comparecencia de otras personas competentes en la materia, aparte de los miembros del Gobierno, autoridades y funcionarios públicos, a efectos de informar y asesorar a la comisión. El criterio, más que por su restricción subjetiva habría de calificarse de «técnico» o «capacitario» en la medida en que pretende auxiliar a la comisión ilustrándola en el conocimiento de la materia sobre que ha de dictaminar.

Ninguna de estas manifestaciones de la presencia de la ciudadanía en los procedimientos de todo orden, incluso el legislativo, que en forma tan incipiente cabría hallar en nuestro ordenamiento, tiene parangón con la idea de consulta tal como se conoce en el ordenamiento suizo que ahora vamos a exponer. La experiencia difiere ostensiblemente pero también la fundamentación de aquellos fenómenos y de este.

La consulta sobre la que nos detenemos, propia del sistema suizo, no está pensada para aportar una posibilidad más de participación en un sistema en que apenas se practica y, por tanto para que sirva de complemento a la de carácter representativo (tal como ocurre entre nosotros); al contrario, más bien ofrece ciertas matizaciones a la participación directa; pues pudiendo manifestarse el cuerpo electoral tras la elaboración parlamentaria de las leyes, y pudiendo hacerlo en sentido opuesto a como se haya concluido por el Parlamento, con las consultas previas se trata que integrar todas las ideas en la elaboración de las leyes más importantes con el fin de evitar (en lo posible) contradicciones entre la labor parlamentaria y la posterior manifestación popular.

4. No cabe confundir en el ordenamiento español las formas de audiencia con el derecho fundamental a participar en asuntos públicos del art. $23 \mathrm{CE}$

La STC 119/1995, de 17 de julio, es una buena prueba de lo afirmado aun cuando no debe desconocerse que las aludidas reivindicaciones actuales eran en aquel año desconocidas, la base de la fundamentación sigue (formalmente) vigente.

Se trataba de la invocación del derecho de participación directa en los asuntos públicos reconocido en el art. 23.1 de nuestra Constitución que los recurrentes consideraron infringido ante la falta de una segunda apertura del trámite información pública de un proyecto urbanístico por parte del Ayuntamiento de Barcelona. Habiendo participado legítimamente en la primera información pública, entendían los recurrentes que la posterior introducción de modificaciones en el Proyecto debió comportar una segunda información pública que, no habiéndose llevado a cabo, les privó de su legítimo ejercicio del

dades del Estado y de las Comunidades Autónomas, para ser informadas sobre cuestiones de su competencia, pero no ha sido empleado para permitir la participación de representantes de grupos sociales en el procedimiento legislativo... 
derecho a participar. En el F. j. 3 de dicha sentencia se explica con claridad la imposibilidad de que tal participación en el trámite de información pública tenga que ver con el derecho de participación en los asuntos públicos reconocido por el art. 23 de la Constitución:

«...la participación directa que en los asuntos públicos ha de corresponder a los ciudadanos es la que se alcanza a través de las consultas populares previstas en la propia Constitución (arts. 92, 149.1,32, 151.2, 167.3 y 168.3)... (que) se refieren a las distintas modalidades de referéndum...Y aún si se admitiera que la Ley puede ampliar los casos de participación directa, los supuestos habrían de ser, en todo caso, excepcionales en un régimen de democracia representativa como el instaurado por nuestra Constitución...».

\section{Una peculiar forma de audiencia: las consultas prenormativas del ordenamiento suizo}

En efecto, los ejemplos reseñados sobre el caso español no son ni pueden llegar a ser comparables con lo que ahora nos proponemos exponer como una de las manifestaciones típicas del régimen constitucional suizo, por lo demás vinculada a la más peculiar de sus notas: la presencia de la voluntad popular en la adopción de decisiones y ahora, también por lo que a la presente reflexión se refiere, incluso en la elaboración jurídica de las mismas. Es decir, que el procedimiento de consulta parte del mandato constitucional por el que, si no todas, al menos las más importantes normas, han de ser conocidas públicamente apenas se plantea su necesidad para que sobre sus contenidos puedan pronunciarse todos lo que hayan de ser sus destinatarios.

Sin perjuicio de la lógica (dentro del sistema suizo) de esta concreta forma de participación, y de su inserción en un proceso evolutivo de progresiva ampliación tanto de la participación ciudadana como de los instrumentos de cooperación federal, no cabe duda que las extraordinarias posibilidades que ofrecen hoy las tecnologías ha facilitado la consolidación del instituto estudiado y, especialmente, las posibilidades de su práctica sin excesivas dilaciones que serian inevitables sin la comunicación y el tratamiento de datos vía telemática.

Con referencia a tal conocimiento público, antes de entrar en la concreta regulación de las consultas en el ordenamiento jurídico suizo, debe subrayarse lo que a mi juicio es llamativo y resulta gratificante para quien se ocupa del estudio de este ordenamiento: el hecho de que toda disposición, incluso en fase de elaboración, se halle «en abierto» con todo tipo de información sobre la misma. Como afirma Gerotto ${ }^{7}$ en las páginas oficiales de la Confederación cabe hallar, junto a

7 Gerotto, Sergio, Svizzera, Il Mulino, Bologna, 2011, p. 145. Sobre el interés de consultar en ocasiones las diversas versiones de las lenguas oficiales, labor que, por lo demás facilita extraordinariamente la 
fuentes del derecho, información sobre su elaboración y planteamientos perfectamente documentados, hasta el punto que en ocasiones constituyen auténticas monografías doctrinales.

\section{PAPEL Y SIGNIFICACIÓN DE LAS CONSULTAS}

\section{1. ¿Otro derecho constitucional de los ciudadanos suizos?: «el derecho de ser consultados»}

Las referencias al régimen suizo siempre vienen marcadas por la admiración y extrañeza que causa la permanente participación popular tanto en la iniciativa de medidas legislativas, y fundamentalmente de las reformas constitucionales, como en la ratificación referendaria de tales decisiones normativas. Tal vez, sin embargo, no sea tan conocida la participación que también cabe hallar en la preparación de las decisiones normativas de suerte que podría afirmarse que desde el mismo planteamiento hasta su final ratificación, está presente la voluntad popular (o, quizás por lo que luego diré, sería más apropiado hablar de voluntad o presencia social). Me refiero al proceso de consultas que poco a poco se ha institucionalizado y regulado conformando una más de las fases de elaboración normativa.

Siendo así, nos hallamos de un lado ante un modo procedimental de escuchar los diversos pareceres de todos aquellos que se consideran interesados en cada medida normativa sometida a tales consultas y, de otro, ante un derecho que se ha ido reconociendo hasta constituir uno más de los derechos de participación del pueblo suizo ${ }^{8}$. Aunque, como se advertía supra, más que una participación general dirigida al cuerpo electoral se trata de una «audiencia social» por cuanto se dirige a grupos sociales que en cada caso se consideran interesados y sobre los que no han faltado críticas de elitismo o profesionalización?.

web oficial de la Confederación, véase Gerotto, Sergio, «Lost (and Found) in Translation, overo l'esperienza della traduzione dei testi normativi in Svizzera e Canada», en Diritto Pubblico Comparato ed Europeo, 2011 III, p. 713 y ss.

8 Gerotto, Sergio, La partecipazione di Regioni e Cantoni alle funzioni dello Stato centrale. Gli ordinamienti italiano e svizzero a confronto. Helbing \& Lichtenhahn, Fribourg, 2004, p. 156. En el estudio comparado de la participación territorial en Italia y Suiza, insiste en la radical diferencia que existe entre ambos ordenamientos en este campo, no solo porque el caso suizo supera la simple consideración de los entes territoriales sino además porque, «como norma, las consultas se fundan en el principio de la más amplia participación».

9 Papadopoulos, Yannis, «La consultation: Un outil de gouvernabilité? Fonctions et dysfonctions de la phase préparlamentaire», en LeGes II, 1997, p. 43. Además de la mayor facilidad con que participan en la consulta los grupos organizados (y profesionales) respecto de los que no lo están, el autor denuncia los efectos que en la práctica de las consultas se producen que pueden llegar a calificarse de «transformación de un sistema de democracia directa en una democracia de negociación» en la medida en que la atención de los poderes públicos es directamente proporcional a la capacidad de cada grupo para promover el referéndum y lograr la adhesión popular. Sin embargo, no puede silenciarse el hecho de que el autor escribía estas y otras críticas a las que me referiré dos años antes de que se aprobara la Constitución del 99 en la que finalmente, y sin perjuicio de los efectos reales a que me iré refiriendo, se constitucionaliza la consulta. 
Ello sin embargo no impide hablar de un derecho de participación pública entre tantos reconocidos constitucionalmente como se confirma en la forma en que se inicia el art. 4 de la Ley: «Toda persona u organización puede participar...». No cabe duda que también esta dimensión subjetiva es deducible del art. 147 de la Constitución ${ }^{10}$ que, bajo el epígrafe de Procedimiento de consulta, establece lo siguiente:

Los Cantones, los partidos políticos y los sectores interesados son consultados en la fase preparatoria de importantes actos legislativos y de otros proyectos de gran calado así como sobre importantes tratados internacionales.

A partir de tal precepto, la Ley federal que regula el procedimiento de Consultas (Ley de Consulta, LCo), de 18 de marzo de 2005, desarrolla sus aspectos básicos encargando en su art. 11 al Consejo federal la ejecución reglamentaria de la misma a través de Ordenanza. Así, la regulación legal de las Consultas se completa con la Ordenanza sobre procedimiento de consulta (Ordenanza sobre consulta, OCo), de 17 de agosto de 2005.

\section{Finalidad institucional y valor integrador de las consultas}

De la normativa reguladora de las consultas debe destacarse, en primer lugar, la fijación que el art. 2 de la Ley hace de los fines de toda consulta: «hacer participar a los Cantones, a los partidos y a los sectores interesados en el proceso de formación de la opinión y de las decisiones de la Confederación». Pero además, en un $2^{\circ}$ párrafo del mismo art. 2 se contiene una referencia a su utilidad (también considerada como fin) al decir que el procedimiento de consultas «proporciona información sobre la congruencia de un proyecto de la Confederación, sobre su viabilidad y sobre el consenso que en torno al mismo exista».

El Mensaje del Consejo federal de 21 de enero de 2004 sobre la (entonces) futura Ley a que me estoy refiriendo era mucho más claro y determinante al haber destacado lo que podríamos denominar papel institucional o naturaleza objetiva del valor de las consultas puesto que ya en sus primeras palabras se expone lo que sería el art. 2 a que me acabo de referir

«El procedimiento de consultas se ha afirmado en Suiza como elemento esencial del procedimiento legislativo y como instrumento central para implicar a los Cantones, partidos y sectores diversos...».

10 Aunque enseguida observaremos que el procedimiento de consulta tiene una significación mucho más amplia, doctrinalmente llama la atención la dimensión federal o institucional de integración cantonal en las decisiones federales. Así, Gerotto, Sergio, La partecipazione di Regioni e Cantoni..., cit., p. 119 y ss. y, entre nosotros, también destaca ese mismo enfoque JARIA Y MANZANO, JORDI, «El federalismo suizo. Una respuesta a una sociedad plural». RVAP, n. ${ }^{\circ} 61,2001$, p. 94. 
Pero, además, de algún modo, se reconoce al procedimiento de consultas cierto papel estructural en el sistema al añadir el propio Informe lo siguiente:

«Como instrumento central de cooperación en el marco del federalismo ha de profundizarse en el procedimiento de consulta para poder contar con la posición particular de los Cantones en tanto que partner ejecutivos de la Confederación.... ${ }^{11}$.

Tal vez en esta simple referencia se contiene la síntesis de lo que un federalismo cooperativo no puede dejar de ser: el ámbito en el que todas las partes contribuyen a conformar la voluntad común que, en consecuencia, se respeta y ejecuta por todos (tal vez rememorando la idea inicial roussoniana del respeto a la voluntad general por tener que ser considerada como la propia).

Que el proceso de consultas se considere un instrumento central es coherente con un federalismo en el que la manifestación de la voluntad popular sobrepasa ampliamente el momento constituyente para constituir un modo de actuación cotidiana, de permanente implicación de todas sus partes en las decisiones generales. En este marco se explica el sistema de consultas.

Partiendo de la generalidad con que en diversos ordenamientos se buscan instrumentos de integración de los actores sociales en las esferas de decisión subraya Papadopoulos la curiosidad e interés del caso suizo puesto que los diversos factores que a ella contribuyen en otros supuestos, en este ordenamiento «se conjugan simultanemente: he aquí un país multicultural, capitalista, muy abierto al exterior y en el que existe la posibilidad de contestar los proyectos gubernamentales mediante el referéndum. No es, por tanto, sorprendente que la consulta haya alcanzado un alto nivel de institucionalización, existiendo fuertes presiones para la obtención de decisiones negociadas ${ }^{12}$.

Ciertamente, su interés no puede ser mayor; no solo desde la perspectiva de la participación popular en todos los ámbitos públicos, sino también sobre la utilidad de la actividad normativa como conformadora de la vida en común a la que proporcione soluciones prácticas, y en definitiva viabilidad, evitando la proliferación de normas absolutamente desconectadas de la realidad o, cuanto menos, rechazadas o no comprendidas por la ciudadanía. En este sentido, la idea de consenso, como elemento esencial del régimen político suizo, se lleva hasta la faceta más técnica de la actividad estatal, aquella en que supuestamente el carácter indirecto de la participación se hallaría más justificado por tratarse de la elaboración de las fuentes del derecho.

11 Para las dos últimas citas textuales, Informe del Consejo federal de 21, de enero de 2004, p. 454. Véase en http://www.admin.ch/opc/search/?source_lang=it\&language $\% 5 \mathrm{~B} \% 5 \mathrm{D}=$ it\&product $\% 5 \mathrm{~B} \% 5 \mathrm{D}=$ fg\&produc$\mathrm{t} \% 5 \mathrm{~B} \% 5 \mathrm{D}=$ oc\&product $\% 5 \mathrm{~B} \% 5 \mathrm{D}=$ cc \&product $\% 5 \mathrm{~B} \% 5 \mathrm{D}=$ ba\&product $\% 5 \mathrm{~B} \% 5 \mathrm{D}=\mathrm{jcd} \&$ date_range_min $=\&-$ date_range_max $=\& d \_c o m p i l a t i o n=b o t h \& d \_i s \_i n \_f o r c e=y e s \& t e x t=$ messaggio + del + Consiglio + federale + $\mathrm{del}+21+$ gennaio $+2004 \&$ lang $=$ it

12 Papadopoulos, YanNis, «La consultation: Un outil de gouvernabilité?...», ya cit., p. 46. 
Y ello aun considerando que, como no podía ser de otro modo, su alcance es informativo, en la medida en que se trata de una actividad eminentemente técnica; pero ello no disminuye la trascendencia de un reconocimiento que institucionaliza y generaliza tan decisiva y permanente presencia social en la elaboración normativa, con el mencionado fin de lograr el consenso sobre la misma:

«Considerada la posibilidad de utilizar el instrumento del referéndum en el ámbito de la democracia suiza, el consenso político logrado en torno a los proyectos de la Confederación tiene un significado relevante para el legislador federal» ${ }^{13}$.

Dando por sentado todo lo afirmado sobre su significación jurídico política, no es menos cierto que los procedimientos de consulta tienen en el ordenamiento suizo una particular significación sin parangón con otros ordenamientos ${ }^{14}$ y justamente en el sentido inverso al que se acaba de reflejar (con referencia a la constante presencia de la voluntad popular en las decisiones públicas): si bien la consulta es muestra de democraticidad y de consenso, también sin embargo, es una especie de restricción o freno a los eventuales efectos disfuncionales de la intervención popular directa sobre las normas tras su aprobación en sede parlamentaria. $\mathrm{O}$, dicho de otro modo, si por una parte trata de lograr y formalizar consensos, de otra, pretende evitar la contradicción entre los acuerdos adoptados parlamentariamente y su posterior ratificación popular. «En esto se sustancia la relación entre la democracia directa (o mejor, semidirecta) y el procedimiento legislativo: el riesgo de ver fracasar a este ha forzado (y se fuerza) la ampliación de los titulares implicados en la preparación legislativa» ${ }^{15}$.

\section{Titulares de la participación o destinatarios de la consulta}

En efecto, la Ley reguladora vigente se refiere a los Cantones pero también a los partidos y sectores potencialmente interesados en la norma. La idea no puede ser más comprensiva pudiendo referirse tanto a grupos de interés como sectores de todo tipo y naturaleza que podrían verse afectados por la norma tras su entrada en vigor ${ }^{16}$. La extraordinaria amplitud de los destinatarios se confirma en la enumeración que contiene el art. 5 de la Ley, referido a la participación ${ }^{17}$. En su primer

13 Informe del Consejo federal de 21 de enero de 2004, p. 466.

14 Entre tantos, J. Roht, La democratie en Suisse, Economica, Paris, 1987, p. 297.

15 Gerotto, Sergio, La apertura democratica del procedimento legislativo svizzero nella fase preparlamentare: funzionamento e ruolo della progettazione legislativa, en Diritto comparato ed europeo. 1999. (17) p. 1287; la idea se desarrolla en pp. 1294-95.

16 En la consulta a que la misma Lco. se sometió las opiniones expresadas fueron divergentes en esta cuestión pues unas propugnaban la ampliación de los destinatarios y otras su reducción con el fin en este caso de lograr suficiente nivel de calidad en la emisión de los pareceres (cfr. Mensaje sobre la Lco de 21 de enero de 2004, ya cit.).

17 El término fue criticado por los Cantones al entender que dicho término es comprensivo de diversos derechos ciudadanos y no puede reconducirse solo a la celebración de las consultas. 
párrafo incluye una cláusula general al decir que «cualquier persona u organización podrá participar en un procedimiento de consulta y responder presentando su propio informe». Y en el segundo párrafo enumera concretos destinatarios que han de ser «invitados» a expresar su propio parecer mencionando en concreto: los Cantones, los partidos representados en la Asamblea federal, confederaciones nacionales de los municipios, de las ciudades y de las regiones de montaña, confederaciones nacionales de la economía y, por último, los otros «sectores» interesados en el caso concreto.

Salvo en lo que se refiere a la última clausula, amplísima ${ }^{18}$, que obviamente dependerá de cada caso, para las otras cuatro menciones enumeradas, existe un Registro o elenco de destinatarios gestionado por la Secretaria General (Cancillería) federal tal como regula la Ordenanza aprobada por el Consejo Federal sobre procedimientos de Consultas (Ordinanza sulla consultazione, $O C_{0}$ ) de 17 de agosto de 2005 (Stato 23 agosto 2005), que se aplica a los procedimientos de Consulta inducidos por el Consejo Federal ${ }^{19}$.

\section{Justificación de su regulación vigente}

Este es un supuesto entre tantos otros que ponen de relieve la tan repetida función de «actualización» que presidió la reforma constitucional suiza de $1999^{20}$. Junto a la profundización en la regulación de las consultas, por lo demás ya antes reconocidas, la forma en que quedan formalizadas en la propia Constitución de 1999 , les ha dado unidad reforzando su posición respecto de su precedente consideración en el ordenamiento. Antes de 1999 se hallaban reconocidas en diversos casos pero en forma puntual y asistemática. El art. 147 de la Constitución no solo eleva su consideración a categoría general sino que refuerza la preocupación (ya manifestada con anterioridad) por elevar el rango de la regulación (de desarrollo constitucional) de las consultas desde la ordenanza a la ley formal.

Por lo demás, la nueva Ley proporcionaba una ocasión excepcional para incorporar al procedimiento las ventajas de las nuevas tecnologías. El momento en que se dictó la Ley reguladora (2005) era, en efecto, oportuno para introducir en el procedimiento el uso de las comunicaciones electrónicas que podían colaborar

18 «... los otros "sectores" interesados en el caso concreto». Bien podría leerse como cualquiera que pueda estar interesado en la concreta acción normativa (en realidad, en sus efectos).

19 Según el ámbito que expresamente determina el art. 1 de dicha Ordenanza; ello sin perjuicio de que al modo en que la misma regula el procedimiento de consultas se acaba por remitir la Ley del Parlamento con referencia a las consultas que parten de las Comisiones parlamentarias por versar sobre proposiciones elaboradas por las Cámaras.

20 La afirmación es general en todos los comentaristas. Ello sin perjuicio de que al final se superara tal propósito inicial entrando en reformas sustanciales: entre otros, Floridia, Giorgio, «Profili di tecnica redazionale dell' «aggiornamento» della costituzione svizzera (ovvero: la forma è sostanza)», in REPOSO, ANTONIO (a cura di), La revisione della Costituzione federale svizzera, Giappichelli, Torino, 2000, p. 23. 
perfectamente en la realización de tales consultas y en la exposición pública de toda la documentación de que se hace uso en ellas por lo que en la nueva ley se incorporó su uso en todos los trámites.

\section{REGULACIÓN VIGENTE}

\section{Iniciativa}

El art. 5 de la Ley de Consultas atribuye la capacidad de su convocatoria a dos titulares: de una parte, el Consejo federal que tiene la iniciativa en los procedimientos de consulta sobre sus propios proyectos de actos normativos (de su competencia); y, de otra, la Comisión parlamentaria competente debe instar el procedimiento sobre los proyectos de actos normativos que le son propios. Iniciado el procedimiento por cada uno de los dos órganos mencionados, el propio art 5, en su párrafo 3, atribuye a la Cancilleria federal la labor de coordinación de todos los procedimientos de consulta, la publicación de las correspondientes iniciaciones de los mismos con la determinación del plazo dentro del cual se puede hacer uso de la participación en cada consulta y con indicación de la oficina o departamento en el que podrá obtenerse la documentación de cada proyecto.

Es asimismo la propia Cancillería federal o el Departamento correspondiente (del que surgió el borrador ${ }^{21}$ quien ha de preparar todo el procedimiento garantizando su normal desarrollo para poder recoger y valorar todas las intervenciones sobre la misma. También puede ocuparse del procedimiento la Comisión parlamentaria que lo haya iniciado coordinando a los servicios de la Administración federal que colaboren en la recogida de los datos (art. 6 de la Ley) ${ }^{22}$. Debe subrayarse el hecho de que este procedimiento queda excluido cuando el proyecto procede de una iniciativa popular, lo que de algún modo confirma la idea de

21 Sobre la indiscutible influencia que ejerce la Administración en los primeros momentos de la preparación (y, por consiguiente, con carácter previo al ejercicio de la iniciativa del procedimiento de consulta), tanto en la designación si procede de la Comisión de expertos como en el nombramiento de su presidente, cfr. Gerotto, Sergio, «La apertura democrática del procedimiento...», ya cit., p. 1290. Sobre la concreta opción suiza entre los diversos enfoques de la relación entre ciudadanos y Administración, RoTHMAYR, CHRISTINE, «¿Diálogo (s) entre los ciudadanos y la Administración en Suiza?», en La nueva gestión pública. Revista Políticas sociales en Europa, n. ${ }^{\circ}$ 17, 2005, pp. 77-89.

22 Este punto viene desarrollado por el art. 112 de la Ley de la Asamblea federal de 13 diciembre de 2002 (Ley del Parlamento, LParl), en el que se regula la colaboración con el Consejo federal y con la Administración federal al disponer lo siguiente: 1. La comisión puede valerse de la colaboración del departamento competente para obtener las informaciones jurídicas y técnicas necesarias para la elaboración de los proyectos normativos. 2. Propone a consulta el proyecto preliminar y su dictamen preparatorio en los términos de la ley de 18 marzo 2005 sobre consultas. Ambos documentos se envían simultáneamente a la Cámara y al Consejo invitando a este a emitir su parecer en plazo razonable; se exceptúan las reformas de carácter organizativo o sobre procedimiento de la propia Asamblea federal no previstas por la ley y que no conciernen directamente al Consejo federal... 
justificación de la consulta en el conocimiento de la opinión popular que, en tales casos resultaría innecesario:

«Puesto que la iniciativa popular no es ni un proyecto del consejo federal ni un proyecto de una comisión parlamentaria, por razones formales contrastaría con la misma concepción de la ley si se enviara para consultas. Además, las autoridades no tienen el derecho de modificar el texto de una iniciativa popular que debe someterse al voto popular en los mismos términos en que se propuso; por tanto, la consulta perdería su razón de ser. Sin embargo, sí cabría que se inicien consultas para el contraproyecto que presente alguna autoridad a la iniciativa popular siempre que el plazo de tramitación de las iniciativas populares lo permita ${ }^{23}$ (cfr. art. 74 LDP).

\section{2. Ámbito de aplicación}

Como vamos a comprobar, su ámbito de aplicación es muy amplio aunque, por el n..$^{\circ}$ III de la LF de 21 de junio de 2013 (de mejora de la organización y procedimientos del Parlamento), en vigor desde el 25 de noviembre de 2013 (RU 2013 3687; FF 20116049 6085), se introdujo el párrafo 1 bis del art. 3 de la Ley, en cuya virtud cabe renunciar a una consulta cuando el proyecto concierne principalmente a la organización o a procedimientos referidos a autoridades federales (es decir, si se regulan cuestiones de organización interna) o, también, si se refiere al reparto de competencias entre ellas. En definitiva, dejan de considerarse necesarias las consultas sobre normas de organización interna de la Administración.

Hecha esta excepción, sin embargo, la amplitud de su ámbito es indiscutible y solo queda matizada por la importancia o relevancia que ha de concurrir en el acto normativo que se tenga que someter a la consulta por ser tal condición la que impone la necesidad, por mandato constitucional, de que se aplique tal procedimiento. Así, el art. 3 de la Ley enumera los siguientes supuestos como actos sometidos a consulta: a) Reformas constitucionales ${ }^{24}$; b) disposiciones legales previstas en el artículo 164. 1 letras a-g de la Constitución federal ${ }^{25}$; c) tratados in-

23 Se refiere a la Ley federal de los derechos políticos, de 17 de diciembre de 1976 de la que el artículo citado posibilitaba la retirada de la iniciativa, precepto que, no obstante, fue abrogado por la LF de 25 septiembre de 2009. Importa sin embargo la reflexión trascrita que es cita literal del Informe del Consejo federal de 21, de enero de 2004, ya cit. (p. 467), por cuanto incide abiertamente en la comprensión de la filosofía que inspira las consultas.

24 Precisamente la exigencia de consultas solo para las normas de mayor relevancia explica que las mismas tengan un protagonismo especial y destacado en los casos de reformas constitucionales. Cfr. GEROTTO, SERgio, «La "dinámica costituzionale” nella Confederacione svizzera: qualche spunto di riflessione sul ruolo dei diritti popolari nel procedimento di revisione costituzionale», en Il Diritto della Regione, n. ${ }^{\circ}$ 5-6, 2009 (Liber amicorum per Nino Olivetti Rason), p. 119 y ss.

25 Una confirmación más de la amplitud del ámbito (de ejecución de esta Ley de consultas) deriva de esta remisión al art. 164. 1 de la Constitución por cuanto en él se afirma que todas las disposiciones impor- 
ternacionales que se someten a referéndum conforme a los artículos 140. 1 letra b) y 141.1 letra d) numero 3 de la Constitución federal ${ }^{26}$ o que afecten intereses esenciales de los Cantones.

Más aún, tal enumeración queda ostensiblemente ampliada en los puntos 2 y 3 del mismo artículo al disponer el primero que se realizara también la consulta sobre proyectos legislativos de calado político, financiero, económico, ecológico, social o cultural o aquellos cuya ejecución haya de confiarse en gran medida a órganos externos a la Administración federal. La amplitud del ámbito difícilmente puede ser mayor. En cuanto al tercer párrafo, establece la obligación, en lo que se refiere a proyectos de ordenanza, de lo que podríamos llamar una consulta institucional territorial, al disponerse en el mismo que también se ha iniciar un procedimiento de consultas (estas dirigidas a los Cantones) cuando ellos sean afectados en forma decisiva por la ordenanza a elaborar.

\section{La forma de intervención}

En lo que se refiere al procedimiento por el que se desarrolla la práctica de la consulta, el art. 7 de la Ley deja claro que, en cuanto a la forma, deberá ejercerse por escrito aunque su transmisión fuera electrónica, debiendo presentarse en el plazo de tres meses que no obstante podrían prorrogarse en atención a periodos vacacionales o a la complejidad del proyecto. Por el contrario, también cabe la posibilidad de que, por razón de urgencia, se proceda a abreviar el plazo de respuesta o participación e, incluso, cabría que. por la misma razón, se desarrollara parcial o totalmente la consulta en forma de conferencia, precisando el art. 17 de la Ordenanza que cabría que se llevara a cabo incluso por grupos; en este caso, se levanta acta de la misma que pasa a conformar uno de los documentos que acompañarán todo el procedimiento.

Previamente a la reforma constitucional de 1999, y con el fin de salir al paso del inconveniente de la dilación temporal y de la complejidad que el sistema de consultas comportaba para la redacción de las normas, se propuso la conveniencia

tantes que contengan normas jurídicas adoptan la forma de ley federal. Ello, en particular, se refiere a las disposiciones fundamentales en materias que a continuación se enumeran: a) ejercicio de los derechos políti$\cos , \mathrm{b})$ restricciones de derechos constitucionales, c) derechos y deberes de las personas, d) determinación de los contribuyentes, objeto y cálculo de los tributos, e) deberes y prestaciones de la Confederación, f) obligaciones de los Cantones en la aplicación y ejecución del derecho federal, g) organización y procedimiento de las autoridades federales....

26 Disponen dichos preceptos constitucionales que se somete a votación del pueblo y de los Cantones (en referéndum obligatorio) la adhesión a organizaciones de seguridad colectiva o a comunidades supranacionales (art. 140.1 a) y que, si 50.000 votantes u ocho Cantones lo solicitan en forma, se someterán a referéndum popular los tratados internacionales: a. de duración indeterminada e indenunciables, b. los que prevean la adhesión a una organización internacional, y c. los que contengan normas de derecho para cuya ejecución sea necesaria la emisión de leyes federales. 
de reducir las consultas a la forma oral con el fin de buscar fórmulas menos formalistas y más ágiles, llegando incluso a proponer la forma de los sondeos con restricción de sus destinatarios al tener que seleccionar los preparados en cada materia quienes teóricamente podrían acabar nutriendo un debate más vivo que el del procedimiento de consultas ${ }^{27}$.

\section{Mecanismo para lograr el consenso social}

Aun cuando la Ley reguladora no la formula expresamente es clara la finalidad de hacer partícipes a todos los eventualmente afectados limando las dificultades que de otro modo pudieran presentarse en la fase parlamentaria de estudio y aprobación de la norma y, también, evitando en lo posible el rechazo de la misma en referéndum en momento posterior a su aprobación por el Parlamento.

En este sentido, junto a la amplísima apertura a posibles participantes que ya he puesto de relieve, debe destacarse la permanente exposición pública de todas las fases del procedimiento y especialmente de la final con aportación de toda la documentación e información complementaria como vamos a ver. En efecto, el art. 8 de la Ley dispone la obligación de que, a partir de las opiniones expresadas, se las sopese y valore, disponiendo el artículo siguiente que deberá ser accesible al público tanto la documentación como las opiniones emitidas en el proceso de consulta y la síntesis de los mismos a partir del momento en que el Consejo fede$\mathrm{ral}^{28}$ los haya recibido. Las formas en que se hace efectiva tal publicidad son varias: puede consultarse todo el dossier en la sede administrativa, o solicitarse copias o ser publicado electrónicamente (sin que les sea de aplicación la Ley de transparencia de 17 de diciembre de 2004, según precisa el pfo. 3 del art. 9).

No todo proyecto tendría, sin embargo, que someterse al procedimiento indicado si se tratara de actos de escasa relevancia. Para tales supuestos, la propia Ley dispone en su art. 10 que el departamento competente o la Cancillería Federal puedan realizar encuestas o sondeos entre las partes interesadas externas a la Administración Federal cuyos resultados, por supuesto, también serán puestos a disposición del público.

\section{La coordinación y colaboración inter órganos}

El Mensaje del Consejo federal de 21 de agosto de 2004, sobre la Ley que venimos citando, ya ponía de relieve en varias ocasiones la importancia de la po-

27 Cfr. Papadopoulos, Yannis, «La consultation: Un outil de gouvernabilité?...», ya cit., pp. 57-58.

28 Ciertamente, la Ordenanza de aplicación detalla el procedimiento intra e interórganos en cuya virtud, acabado el proceso de consulta, ha de remitir al Consejo todos los resultados y valoraciones. 
sición sistemática del precepto constitucional que reconoce el deber de consulta (art. 147). Al hallarse en las disposiciones generales del Título Quinto regulador de las Autoridades federales, hay que deducir que obliga a todas ellas, tanto a la Asamblea y al Consejo federal como al Tribunal federal, aunque de las competencias atribuidas a este por su propia Ley reguladora no cabe esperar que el Tribunal tenga que poner en marcha ningún tipo de consulta desde el momento en que no puede elaborar disposiciones relevantes a las que se refiere el art. 147 de la Constitución quedando, por consiguiente, en la práctica, tal obligación general, reconducida a los órganos ejecutivo y legislativo. Sin perjuicio, por supuesto de la eventual defensa jurisdiccional que cabría impetrar de ser ignorado algún destinatario o alguno de los formalismos garantistas de los previstos en la Ley.

No obstante ello, dentro de las fases del procedimiento sí se halla prevista la invitación al Tribunal, y otras autoridades judiciales de la Confederación, para que emitan su parecer respecto de proyectos que afecten a los procedimientos propios de sus competencias; incluso, en concreto sobre proyectos que afecten al estatuto la organización o administración del Tribunal federal o de otra autoridad judicial de la Confederación que se viera afectada, se dispone la obligación de que se les invite a manifestarse al respecto antes de que se proceda a iniciar la consulta solicitando sus pareceres y ello sin perjuicio de que, iniciado el procedimiento de consulta, volverán a ser consultados (art. 11 de la Ordenanza).

\section{FASES DEL PROCEDIMIENTO DE CONSULTA SEGÚN LA ORDENANZA DE 17 DE AGOSTO DE 2005}

De conformidad con la habilitación contenida en el art. 11 de la Ley, el Consejo federal dicta la Ordenanza por la que reglamentan todos los particulares de la ejecución y coordinación de los diversos procedimientos de consulta que dicho órgano inicia. La ahora vigente, como ya se ha dicho, es del 17 de agosto de 2005 y de la misma, vale la pena recordar los siguientes extremos:

A) Cualquiera que sea el órgano del que procede la propuesta de inicio del procedimiento (que, también se ha dicho, se formalizará por el Consejo federal) a toda encuesta iniciada con tal fin se le aplicaran las siguientes disposiciones:

a) Inclusión en la planificación semestral que se habrá de realizar por los departamentos y la Cancillería tal como dispone el art. 3 de la Ordenanza ${ }^{29}$.

29 De conformidad con el art. 5 de la Ordenanza la Cancillería Federal informará cada seis meses, al Consejo Federal, a las oficinas de los dos Consejos, a los cantones, a los partidos políticos y a los medios de comunicación acerca de las consultas previstas, cuya relación deberá además publicar electrónicamente en el mismo período quedando, por consiguiente a disposición del público (art. 3.2,b y art. 12.3). 
b) Preparación de un informe sobre los resultados obtenidos. Dicho informe ha de referir las opiniones emitidas y resumir sus contenidos en forma comprensible y sin juicios de valor; caso de que se trate de consultas por sistema de conferencia, el informe sobre los resultados incluirá también el acta de la misma (art. 20).

c) La publicidad, presente en todas las fases, se llevara a cabo en la forma que establecen los arts. 12 y 21 de la Ordenanza: en este último se dispone que inmediatamente, en cuanto el Consejo federal adopte la decisión de concluir el procedimiento, se informará por la Cancillería a los medios de comunicación y se hará público electrónicamente el informe de los resultados al tiempo que el órgano administrativo competente informara a los participantes en la consulta de que se ha publicado el informe indicándoles la dirección electrónica donde puede ser consultado. Pero no es menos significativo que también se haya de comunicar a la prensa el acuerdo de iniciación del procedimiento según el art. 12. 1 de la Ordenanza y ello sin perjuicio de que el pfo. 3 del mismo artículo ordene su inmediata publicación electrónica.

B) La coordinación de la tramitación de todas las consultas en curso es competencia de la Cancillería a cuyo propósito todos los departamentos han de informarle sobre las consultas que hayan previsto realizar debiendo precisar el título de la futura norma en las tres lenguas oficiales y el plazo para la recepción de las opiniones. Los proponentes acordarán con la Cancelleria si en cada caso procede una consulta o una encuesta (art. 4 de la Ordenanza).

C) En lo que se refiere al razonamiento, o motivación, con que se ha de presentar cada propuesta que se presente al Consejo, los artículos 6 a 9 determinan con detalle la que debe presentarse y la forma en que debe hacerse. El art. 6 regula la forma en que han de hacerse por los respectivos departamentos las propuestas al Consejo federal con el fin de que este pueda iniciar el procedimiento pero sin duda lo más significativo es la serie de exigencias documentales que enumeran los dos artículos siguientes. Por lo que se refiere a la propuesta que se haga al Consejo federal para que inste un procedimiento de consulta, exige el art. 6 que en la misma se expliciten los siguientes extremos:

a) si el mismo ha de desarrollarse por la vía del art. 3.1 o por la del 3.2 de la Ley reguladora ${ }^{30}$.

b) la razón por la que, si procede, se elige el método de consulta por conferencia.

c) la razón por la que, de solicitarse, debería aplicarse la previsión legal de reducción de plazos.

30 Según se vio supra tales párrafos enumeran los tipos de actos normativos sujetos, por mandato constitucional, a consulta todos los cuales deberán ser relevantes. 
D) Sobre la documentación explicativa que se ha de adjuntar a cada propuesta no es menos exigente la Ordenanza al enumerarla su artículo 7 del siguiente modo: se acompañará con los borradores de la documentación y de los comunicados dirigidos a la prensa. Por documentación han de entenderse los siguientes elementos ${ }^{31}$ :

a) El anteproyecto que se ha de someter a consulta.

b) El informe razonado sobre el mismo.

c) Las cartas dirigidas a los destinatarios del anteproyecto y, por consiguiente, interesados en la participación en la consulta.

d) La enumeración de tales destinatarios.

E) Además, el anteproyecto se deberá acompañar de un informe justificativo de cuyo contenido se ocupa el artículo 8 de la Ordenanza disponiendo que deberá dar una visión de conjunto del mismo, explicando sus principios y objetivos y refiriendo las indicaciones y directrices pertinentes para su aplicación. Si se trata de anteproyectos articulados se comentaran las concretas disposiciones y en lo demás se aplican por analogía las directrices generales establecidas para la redacción de los mensajes del Consejo federal.

F) Todos los adjuntos al anteproyecto se completan con una «carta acompañadora» dirigida a los destinatarios de la norma cuyo contenido queda determinado en el art. 9 de la misma Ordenanza en los siguientes términos:

a) Una remisión al acuerdo de iniciativa.

b) Determinación del plazo para responder a la consulta.

c) Si procede, cuestiones planteadas sobre los aspectos esenciales del proyecto.

d) La dirección electrónica donde se puede encontrar toda la documentación.

e) Junto a dicha carta se incluye otra dirigida a los Cantones que se dirigirá a los respectivos Gobiernos.

G) Además de la ya aludida comunicación a la prensa y la publicación electrónica del acuerdo de inicio y de toda la documentación aneja, la Unidad administrativa competente, de conformidad con el art. 14 de la Ordenanza, habrá de enviar dicha documentación a los destinatarios de la consulta.

H) Publicación de las opiniones emitidas y, si la consulta se celebró por el procedimiento de conferencia, también de su correspondiente acta. De conformidad con el art. 9.1 de la Ley y 16 de la Ordenanza, se llevara a cabo tal publi-

31 Que, según dispone el pfo. 3 del mismo art. 7 se facilitarán en las tres lenguas oficiales, salvo que se trate de acuerdos internacionales para los que bastaría con una o dos lenguas oficiales. 
cación apenas finalice el plazo para que pudieran ser emitidas las correspondientes respuestas.

I) La finalización del procedimiento se produce con la propuesta dirigida al Consejo federal en la forma que regula el art. 8 de la Ley y el 18 de la Ordenanza al disponer que se hará valorando y ponderando en forma sintética los resultados de la consulta y teniendo muy en cuenta las opiniones de los Cantones cuando se trate de transposición o ejecución del derecho federal. Si existen dudas sobre el sentido de los pronunciamientos emitidos en alguno de los aspectos concretos, se formulará una propuesta al respecto. Por último, el art. 19 de la Ordenanza refiere los anexos que (en las tres lenguas oficiales) deben acompañar a la propuesta final dirigida al Consejo:

a) Informe de resultados.

b) El anteproyecto y, si se tratara de un texto dirigido a la Asamblea federal, el borrador del mensaje.

c) Borrador de los comunicados a la prensa.

d) Caso de que el Tribunal federal lo pida, deberá reproducirse su opinión completa en el mensaje.

\section{ALGUNA VALORACIÓN PARA CONCLUIR.}

\section{Valoración jurídico formal}

A) La forma exhaustiva en que se regula el procedimiento de las consultas deja poco margen a la discrecionalidad de sus aplicadores. Más bien nos hallamos ante el establecimiento de unos protocolos de actuación con cierto automatismo en sus fases sucesivas, tan detalladas que es difícil imaginar capacidad alguna del funcionariado para desarrollarlo al margen de la norma en la medida en que esta no deja resquicio alguno por contemplar ${ }^{32}$.

Ahora bien, si ello es indiscutible en lo que se refiere a los protocolos formales del procedimiento de consulta que acabamos de sintetizar, no es menos cierta la capacidad de influencia de que dispone la Administración no solo por su función de reordenar y valorar las opiniones expresadas sobre cada anteproyecto, sino fundamentalmente por el carácter técnico de sus funcionarios que contrasta con la escasez de medios de los parlamentarios que, con posterioridad a la consulta,

32 Apuntaba al inicio de esta reflexión la extraordinaria completitud de la información facilitada por la página oficial de la Confederación (http://www.admin.ch/) sobre cualquier materia de interés. Pues bien, en la aquí estudiada se llega al extremo de incluir un completísimo esquema del procedimiento. Hasta 4 folios ocupa el referido esquema perfectamente visible en la primera página en cuyo pie, entre lo que incluye como «Asuntos políticos» o dossieres, se incluye este de «procedimiento de consultas y encuestas». Dicho amplísimo esquema o mapa conceptual puede consultarse en: file://C:/Users/user/Downloads/Ablaufschema_Vernehmlassungen_Anh\%C3\%B6rungen_i.pdf 
habrán de discutir el proyecto ${ }^{33}$. Pero tal vez lo más significativo sea la permanente exposición pública de todas las actuaciones de la Administración y, también la de todos y cada uno de los sectores interesados y, por tanto participantes en la consulta, y del contenido de sus manifestaciones en ella. Ello sin duda añade un componente de responsabilidad y de referentes y exigencia de coherencia que en absoluto cabria valorar si se actuara solo por lobbies en ejercicio de su labor de influencia ${ }^{34}$.

B) Según se dijo supra, la práctica de estas consultas ha acabado configurando un derecho popular más lo que, desde luego, se halla bien lejos de los actuales intentos de aproximar la ciudadanía a la labor parlamentaria en ordenamientos representativos como es nuestro caso concreto. El recientísimo trabajo de Manuel Carrasco $^{35}$ sobre la participación social en el procedimiento legislativo ilustra sobradamente acerca de los intentos de aproximar a la labor parlamentaria aquellos sectores representativos de intereses sociales concretos en permanente invocación de la necesidad de ampliar la participación ciudadana y de legitimar lo más posible la labor de los representantes políticos en un momento en que el distanciamiento entre unos y otros se ha convertido en un clamor ${ }^{36}$.

No es tal, como se habrá podido comprobar en este estudio, el planteamiento, ni la finalidad, ni la naturaleza de la consulta en el ordenamiento jurídico suizo. No ya porque llegue a configurar un derecho cuyo ejercicio dista mucho de exigir a priori una determinada especialidad o preparación como en los casos que relata Carrasco (en los que de algún modo se trata de ilustrar a las Cámaras sobre cuestiones temáticas o supuestos concretos), sino que se ejercita por el solo hecho de ser destinatario de la norma. Es que, además, no se trata de ninguna medida o participación excepcional que pueda legitimar la concreta norma cuyo estudio parlamentario se prepara, sino que forma parte de la actuación ordinaria o habitual del cuerpo electoral y de su permanente intervención en el proceso evolutivo del ordenamiento jurídico suizo.

33 Cfr. Gerotto, Sergio, «La apertura democrática del procedimiento...» ya cit., p. 1296. Frente a la acusación de falta de democraticidad del procedimiento de consulta por esta constante presencia en él de la Administración, sostiene el autor que «no carece de cierta dosis de sentido común la decisión de haber confiado en la Administración un papel tan relevante en la preparación de los textos legislativos. Si, en efecto, a la Administración compete aplicar las leyes y si el contenido normativo de las mismas deriva de la aplicación concreta que de las mismas se haga, nada más apropiado que hacer que la Administración participe ya en la fase preparatoria».

34 Sobre las propuestas para la regulación en España del fenómeno y el recrudecimiento de las mismas y de la polémica en torno a la nueva legislación sobre transparencia, Álvarez VÉLEZ, M. ${ }^{a}$ ISABEL y De MoNTALVO JäÄSKELÄINEN, FEDERICO, «Los lobbies en el marco de la Unión Europea: una reflexión a propósito de su regulación en España», en Teoría y Realidad Constitucional, n. ${ }^{\circ} 33,2014$, p. 353 y ss.

35 Carrasco Durán, Manuel, «La participación social en el procedimiento legislativo», en UNED. Revista de Derecho Político, n. ${ }^{\circ} 89$, enero-abril 2014, p. 175 y ss.

36 La invocación hoy de nuevos medios de participación dista mucho, desde luego de los clásicos medios de participación que quedaron reflejados, hace solo 13 años, en la obra de referencia, detallada y exhaustiva, de Castellá Andreu, Josep M.a.: Los derechos constitucionales de participación política en la Administración pública (Un estudio del art. 105 de la Constitución), CEDECS, Barcelona, 2001. 
Todo ello conforma un corpus teórico y constitucional sin perjuicio de la ya aludida dificultad que, para emitir sus opiniones, encuentran los grupos sin la suficiente organización y sin la concreta preparación técnica y la consecuente preeminencia que en los procedimientos de consultas alcanzan los grupos más fuertes y profesionalizados que logran más fácilmente negociar con las autoridades proponentes.

Esta eventual disfunción «elitista» o capacitaria no impide, sin embargo, que con posterioridad a la aprobación parlamentaria pueda llegar a pronunciarse en contra la voluntad popular en la medida en que, como recuerda Papadopoulos, la democracia directa puede llevar a efectos imprevisibles: «no solo da lugar a cambios de posición de los actores institucionales sino que el comportamiento de los electores no siempre responde a las recomendaciones de los mismos: la disciplina de voto de los simpatizantes de un partido es más débil que la de los miembros de su grupo parlamentario que, ya de por sí, no es fuerte en Suiza...» ${ }^{37}$

C) En realidad, si hubiera de hallar una justificación última al instituto estudiado, sería más de carácter práctico que dogmático en la medida en que el procedimiento de consultas favorece el conocimiento de la norma que, con posterioridad a su aprobación parlamentaria, se someterá al voto popular ${ }^{38}$.

Merece por ello la pena que también finalicemos con una valoración política que, a diferencia de los supuestos estudiados por Carrasco, alcanza un amplísimo calado por cuanto, más que tratar de apuntalar y mejorar un concreto órgano o procedimiento, es expresión pura y simple (natural, cabría decir) de un régimen peculiar en el que es bien poco lo que se puede hacer sin el asenso popular. De ahí que, junto a la aludida capacidad de influencia de grupos organizados y/o de interés, habrá de atenderse a aquellos destinatarios que podrían aunar votos populares (en el posterior referéndum) suficientes para decidir sobre el buen fin de la norma.

\section{Valoración política}

A) Siendo bien conocida la multiplicidad de variantes de aplicación de la idea federal, resulta difícil establecer criterios que pudieran acomunar experiencias diversas de federalismo. Es frecuente encontrar como su más destacada característica la concurrencia de diversidades territoriales y ello que es cierto, en el caso suizo alcanza su máxima expresión a su largo de la historia. Ahora bien, ha de subrayarse a mi juicio la perspectiva contraria que tal vez hoy en España de-

37 Papadopoulos, YanNis, «La consultation: Un outil de gouvernabilité?...», ya cit., p. 52.

38 En este sentido, afirma GEROTTO («La “dinámica costituzionale” nella Confederacione svizzera: qualche spunto di riflessione...», ya cit., p. 130) que el interés de la fase pre parlamentaria de proyección legislativa reside en el hecho de que la misma se inserte en la lógica consensual-compromisoria que inspira al ordenamiento suizo, siendo expresión de la tendencia suiza al espíritu pragmático para la solución de problemas y la influencia de la democracia directa en toda manifestación institucional. 
biera constituir un punto de inflexión en el pensamiento y el debate político, en particular a la hora de considerar las propuestas de proseguir y profundizar en la autonomía constituyendo un Estado federal.

Me refiero a la voluntad de todas las partes de permanecer unidas participando (y negociando) en la adopción de las decisiones comunes y, en consecuencia, a la estructuración de técnicas y sistemas que permitan conformar todas las decisiones importantes (así las califica la Constitución suiza y la normativa con la que hemos expuesto aquí el derecho de ser consultado) con la máxima participación de las partes implicadas, lo que en el caso suizo, como se acaba de ver, no solo se refiere a la intervención de los diversos territorios sino también de todos los sectores sociales que han de verse afectados por cada una de las decisiones.

Pero este concreto aspecto constitucional sobre el que he reflexionado no puede comprenderse en forma aislada del conjunto ordinamental, de sus valores y principios. De ahí la dificultad de exportar este tipo de prácticas a otros ordenamientos.

No cabe negar que en nuestro caso la decisión fundamental formalizada en la Constitución de 1978 contó con el asenso de todos los territorios, aun cuando formalmente no se hallaban constituidos (aunque sí algunos preconstituidos). Pero no cabe negar que una fuerte exigencia de autonomía y participación (preferiría decir integración federal) ha de hallar notables deficiencias en lo que afecta a la aplicación posterior a la declaración de principios contenida en la Constitución. Y, más aún, la deficiencia es incontestable en lo que se refiere a la participación social (o de los diversos sectores e intereses sociales) que en nuestro caso carece de la institucionalización que acabamos de observar en el caso suizo.

Y cabría decir más: la base sobre la que se establecen estas intervenciones en la labor prelegislativa es vista con malos ojos en otros países en la medida en que de lo que se trata es de consensuar, de lograr un compromiso (lo que jurídicamente no tendría por qué ser un valor ${ }^{39}$. Pero lo llamemos consenso, cooperación o colaboración es obvio que toda propuesta federal ha de comportar la integración de los diversos territorios y por consiguiente el establecimiento de mecanismos e institutos diseñados al efecto que hoy se hallan absolutamente ausentes en nuestro sistema.

Volviendo en esta misma línea de pensamiento al caso suizo, en él sería inconcebible la adopción de decisiones de calado sin la intervención de todos y cada uno de los Cantones y el caso aquí expuesto, con todos sus inconvenientes de dilación e incluso de inmovilismo, es un claro exponente de tal integración territorial.

B) Ya se ha aludido a la valoración contenida en el Mensaje del Consejo federal de 21 de agosto de 2004 sobre el proyecto que acabaría convirtiéndose en la Ley de Consultas de 2005: junto a su condición de instrumento de integración y cooperación de los Cantones, partidos y sociedad en la elaboración de la voluntad

39 Gerotto, Sergio, «La "dinámica costituzionale” nella Confederacione svizzera: qualche spunto di riflessione sul ruolo...», ya cit., p. 131. 
de la Confederación y en sus diversas manifestaciones normativas, el procedimiento de consulta se define como instrumento central de cooperación federal en la medida en que la ejecución de tal voluntad federal se halla en manos de los territorios; por ello, la participación de estos en la adopción de las medidas normativas de mayor relevancia facilita el establecimiento de medidas que no solo entraran en vigor con la garantía de contar con el mayor consenso posible sino que, además, habrán sido preparadas teniendo en cuenta el parecer de quienes han de aplicarlas, ponerlas en práctica y acatarlas.

En este planteamiento integrador no cabe desconocer que son destinatarios privilegiados de las consultas los Cantones que, tras la entrada en vigor de la norma serán también los llamados a aplicarla. Y es justamente su intervención en la fase prenormativa la que explica la escasa conflictividad de las relaciones centro periferia de que ha de ocuparse el Tribunal federal; explica Gerotto ${ }^{40}$, en este sentido, que la Constitución en su art. 188.1, d) sí reconoce a dicho Tribunal la competencia para resolver los conflictos territoriales y no es precisamente por self restraint del mismo que apenas se planteen dichos conflictos sino por la particularísima forma de desarrollo del procedimiento legislativo a través de las consultas que permiten la integración en cada proyecto legislativo de las posiciones de los Cantones, lo que a Papadopoulos le lleva hasta poder considerarlas un instrumento de gobernabilidad ${ }^{41}$.

La cuestión, por lo demás, sobrepasa la simple consideración organizativa y territorial para residenciarse en cierto sentimiento de integración (en realidad, sentimiento constitucional) que acaba caracterizando la cultura política de un pueblo como el suizo que en ciertos aspectos como el que ahora nos ocupa sigue siendo paradigmático. Por ello, Linder ${ }^{42}$ recuerda la fuerte implicación de las estructuras políticas suizas con la cultura política de sus ciudadanos. Pues, en última instancia, el federalismo es pluridimensional y es la concreta combinación de sus tres dimensiones (que Eleazar determina en torno a una estructura, un proceso y una cultura política) la que surte las múltiples combinaciones que dan lugar a sus bien diversas manifestaciones estatales. Y, en tal sentido, es obvio que EEUU, Canadá o Suiza se diferencien de otras experiencias federales que surgieron a partir de Estados centralizados en la medida en que en tales tres casos es el Estado el que surge de la federación de entidades preexistentes.

El aspecto tal vez más significativo, tras su conformación como Estados, es la forma en que Suiza ha seguido poniendo frenos a la centralización precisamente a través de la permanente intervención de Cantones y del cuerpo electoral en

40 Gerotto, Sergio, «Giurisprudenza costituzionale in Svizzera nel bienio 2002-2003», en Giurisprudenza Costituzionale, año XLIX, fasc. 5-2004, p. 3662 y ss. (idea confirmada en las reseñas jurisprudenciales de los bienios sucesivos, en la misma publicación).

41 Papadopoulos, Yannis, «La consultation: Un outil de gouvernabilité?...», ya cit., p. 47 y ss.

42 Linder, Wolf, «Fédéralisme Suisse et culture politique», en Mazzolleni, Oscar (a cura di), Federalismo e decentramento/Fédéralisme et décentralisation. L'esperinza svizzera e le nuove sfide europeel L'expérience suisse et les nouveaux défis européens. Giampiero Casagrande, Milano, 2005, p. 43. 
cuantas decisiones han podido comportar la asunción de alguna competencia nueva por parte de la federación (ex art. 3 de la Constitución ${ }^{43}$.

C) Pero la cuestión decisiva es que tal resistencia a las lógicas tendencias centralizadoras no se plantea en términos de ruptura o de enfrentamiento sino de «natural» (e indiscutida) integración de todas las partes y elementos de la federación en la conformación de la voluntad general y en su permanente evolución. El caso aquí expuesto es un buen ejemplo de la naturalidad con que tal integración federal se produce. Ahora bien, como precisa Linder, solo el principio federal no podría explicar el fenómeno suizo en el que la democracia consensual pesa tanto como el federalismo. La amalgama suiza entre federalismo y democracia consensual no es sino la combinación de un reparto de poder vertical y también horizontal y si bien esta cultura del consenso permite explicar tantos comportamientos y resultados logrados por los suizos, no basta solo el elemento de la cultura política para que de la misma derive el complejo equilibrio por ellos logrado; también es necesaria la previsión institucional y procedimental de institutos formalizados en su propio ordenamiento no solo con vistas a respetar el consenso sino también para forzarlo a través de los points de veto que, aparte de estimularlo, han obligado al consenso ${ }^{44}$. El procedimiento aquí explicado es un caso paradigmático.

D) La eficacia que las consultas, sumadas a otros elementos institucionales y culturales suizos, despliegan en el campo de la integración no impiden sin embargo algunas disfunciones del sistema entre las que, para concluir, basta con citar la tendencia al conservadurismo que parece derivar del carácter consensuado de las decisiones y que entre nosotros tendría una muy negativa recepción. Papadopoulos recuerda que los procesos de consultas suelen concluir con soluciones poco alejadas del statu quo, del que lo mayores beneficiarios suelen ser los más influyentes en la medida en que su poder de chantaje permite avistar el temido referéndum negativo; y con ello no se refiere solo a los grupos poderosos, «paradójicamente, es la mayor apertura del sistema político a su entorno social el que refuerza el conservadurismo (puesto que) ...el potencial de chantaje de los actores consultados lleva a las autoridades a descartar las propuestas más innovadoras y a mantener las que no afectan demasiado a los derechos adquiridos...» ${ }^{45}$. Lo que, por lo demás, tampoco rompe con la dinámica generalmente conservadora que se deja sentir en el sistema suizo de democracia semidirecta que ha llevado, incluso a merecer reproches desde la perspectiva del respeto a los derechos humanos y de sus compromisos internacionales en tal ámbito. Pero ello ya es objeto de otra cuestión ${ }^{46}$.

$$
* * *
$$

43 Ibidem, p. 45.

44 Ibidem, pp. 54 a 56.

45 Papadopoulos, Yannis, «La consultation: Un outil de gouvernabilité?...», ya cit., pp. 46-47.

46 Por todos, Mahon, PASCAL, «L'espulsione degli stranieri nel recente referendum costituzionale svizzero», en Quaderni Costituzionali, marzo, 2001, p. 147 y ss. 
Title: A Mechanism of Federal and Citizen Integration: Consultations «Pre Regulations» in the Swiss Constitutional Order

ABSTRACT: In the latest demands to enable an increase in popular participation in any democratic government, once more Switzerland offers a very curious example. In this study can be seen the constitutional and legal regulation for the consultation like the process in which, the citizens in Switzerland contribute in the elaboration of the law, expressing their views when the Government is preparing some important legislation. It can be considered another constitutional right; but at the same time it is a mechanism for territorial integration and citizenship in a system chaired by the permanent expression of the popular will.

RESUMEN: En las recientes reivindicaciones de mayores medios de participación democrática, como contestación a la simple participación mediante representantes elegidos, Suiza nos ofrece, una vez más, un ejemplo muy curioso. Este es un estudio sobre la regulación constitucional y legal del proceso de consultas a través del cual los ciudadanos dejan sentir su voz en todo proyecto normativo relevante. Puede ser considerado un derecho constitucional más pero, a la vez, es un mecanismo de integración territorial y ciudadana en un sistema presidido por la permanente manifestación de la voluntad popular.

KEY WORDS: Participation right, Legislative process.

Palabras Clave: Derecho de participación, Actividad normativa.

FECHA DE RECEPCIÓN: 20.01.2015

FeCHA DE ACEPTACIÓN: 29.07.2015 